\title{
Gambaran Monitoring Gula Darah Kasus Diabetes Melitus di Puskesmas 'X' Kota Dumai
}

\author{
Elda Nazriati,,$^{*}$ Fifia Chandra, ${ }^{2}$ Izfhathaniah, ${ }^{3}$
}

\begin{abstract}
Diabetes mellitus is a metabolic disease that has 2 main targets of treatment, keeping the glucose levels within normal range, and preventing complications. The purposed of this research is to know the description of blood glucose monitoring consisting of fasting blood glucose, HbA1C, and self monitoring blood glucose (SMBG). This was a qualitative research by using observation method and deep interview to ten informant. The results showed the checkup of fasting blood glucose levels have been going well with some obstacles, for instance, running out of glucose strips. Puskesmas ' $\mathrm{X}$ ' did not perform HbA1C checkup due to unavailability of laboratory equipment. Overall DM patients did not perform SMBG because they did not have the device, but the researchers obtained one patient who had a device at home, but the patient still chose to check his blood glucose at the puskesmas because the low knowledge of the patient to perform SMBG.
\end{abstract}

Keywords: blood glucose, diabetes melitus, monitoring.

Diabetes melitus (DM) merupakan penyakit metabolik yang ditandai oleh hiperglikemia akibat kegagalan sekresi insulin, kerja insulin atau keduanya. ${ }^{1}$ Penyakit ini bersifat kronis dan jumlah penderitanya terus meningkat di seluruh dunia seiring dengan bertambahnya jumlah populasi, usia, prevalensi obesitas dan penurunan aktivitas fisik. Akibatnya, jumlah penderita akan menjadi dua kali lipat pada dekade berikutnya sehingga akan menambah beban biaya pelayanan di bidang kesehatan terutama di negara berkembang. ${ }^{2}$

Berdasarkan hasil Riset Kesehatan Dasar (Riskesdas) pada tahun 2013 secara nasional menunjukkan bahwa prevalensi DM berdasarkan wawancara yang terdiagnosis oleh dokter dan adanya gejala adalah sebesar $2,1 \%$. Prevalensi diabetes yang terdiagnosis dokter tertinggi terdapat di Yogyakarta 2,6\%, DKI Jakarta 2,5\%, Sulawesi Utara 2,4\%, dan Kalimantan Timur 2,3\%. Sementara

\footnotetext{
* Korespondensi penulis : eldanazriati@gmail.com

1 KJFD Pendidikan Kedokteran Fakultas Kedokteran Universitas Riau

2 KJFD Ilmu Kesehatan Masyarakat Fakultas Kedokteran Universitas Riau

3 Mahasiswa Fakultas Kedokteran Universitas Riau
}

data untuk Provinsi Riau sendiri didapatkan angka 1\%. ${ }^{4}$ Pada Provinsi Riau, Kota Dumai menempati urutan pertama jumlah penderita DM dengan prevalensi $1,7 \%{ }^{3}$

Secara umum tujuan penatalaksanaan DM adalah meningkatkan kualitas hidup penyandang diabetes. Demi tercapainya tujuan tersebut maka perlu dilakukan pengendalian glukosa darah dengan cara memonitor kadar gula darah pasien DM. Konsensus pengelolaan dan pencegahan diabetes melitus tipe 2 di Indonesia tahun 2015 menjelaskan, bahwa salah satu penatalaksanaan diabetes melitus adalah monitoring kadar glukosa darah yang terdiri dari pemeriksaan glukosa darah, pemeriksaan HbA1C, dan pemantauan glukosa darah mandiri (PGDM). ${ }^{4}$

Ruang lingkup penelitian ini adalah untuk menggambarkan proses pelaksanaan, pencatatan, fasilitas, kendala dan upaya dalam monitoring gula darah kasus diabetes melitus di Puskesmas ' $\mathrm{X}$ ' Kota Dumai, yang terdiri dari pelaksanaan pemeriksaan gula darah, HbA1C dan pemantauan glukosa darah mandiri pada pasien yang mendapat anjuran pemeriksaan tersebut. 


\section{METODE}

Penelitian ini menggunakan metode kualitatif dengan teknik pengumpulan data in depth interview. Penelitian dilakukan pada bulan Januari-Juni 2018 di Puskesmas ' $X$ ' Kota Dumai. Sampel penelitian untuk gambaran program monitoring, peneliti menggunakan cara purposive yaitu pemilihan subjek penelitian berdasarkan suatu pertimbangan yang memahami dan memiliki informasi yang diinginkan. Pemilihan sampel untuk pasien DM menggunakan teknik snowball sampling. Adapun yang akan menjadi sampel untuk meneliti gambaran program monitoring adalah yang memenuhi kriteria inklusi, yaitu kepala Puskesmas atau staf yang mengetahui tentang program monitoring DM di Puskesmas Dumai Barat, dokter yang bertugas di Puskesmas Dumai Barat, perawat yang bertugas di Puskesmas Dumai barat, pasien DM dengan usia diatas 18 tahun yang telah berobat lebih dari 6 bulan dan bersedia diwawancarai serta didapat dari rekomendasi baik oleh obyek yang sudah pernah diwawancarai maupun informasi lainnya.

\section{HASIL}

\section{Gambaran Umum informan monitoring gula darah kasus diabetes melitus}

Tabel 1 Karakteristik Informan Wawancara Mendalam

\begin{tabular}{|c|c|c|c|c|c|}
\hline No & Informant & Jumlah & Umur & $\begin{array}{c}\text { Jenis } \\
\text { kelamin }\end{array}$ & $\begin{array}{c}\text { Pendidikan } \\
\text { terkakhir }\end{array}$ \\
\hline \multirow[t]{4}{*}{1} & Informan kunci & & & & \\
\hline & Pemegang Program PTM & 1 & 37 & $\mathrm{P}$ & D3 \\
\hline & Dokter Umum & 1 & 35 & $\mathrm{P}$ & S1 \\
\hline & Perawat & 1 & 37 & $\mathrm{P}$ & D3 \\
\hline \multirow[t]{8}{*}{2} & Informan utama & & & & \\
\hline & Informan 1 & 1 & 61 & $\mathrm{~L}$ & SD \\
\hline & Informan 2 & 1 & 63 & $\mathrm{P}$ & SMP \\
\hline & Informan 3 & 1 & 67 & $\mathrm{P}$ & SD \\
\hline & Informan 4 & 1 & 65 & $\mathrm{P}$ & SD \\
\hline & Informan 5 & 1 & 53 & $\mathrm{~L}$ & SMP \\
\hline & Informan 6 & 1 & 58 & $\mathrm{P}$ & SMP \\
\hline & Informan 7 & 1 & 61 & $\mathrm{P}$ & SMP \\
\hline
\end{tabular}

Karakteristik informan banyak berusia diatas 50 tahun seperti yang terlihat pada tabel 1 . Didapatkan juga informasi bahwa 3 dari 7 informan tingkat pendidikan terakhirnya adalah sekolah dasar (SD) dan informan lainnya memiliki tingkat pendidikan terakhir sekolah menengah pertama (SMP).

Hasil wawancara yang dilakukan dengan dokter yang bertugas di puskesmas ' $\mathrm{X}$ ', didapatkan bahwa dalam 1 hari jumlah pasien DM di poli lanjut usia paling banyak bisa mencapai 10 orang, terbukti pada tahun 2017 jumlah kunjungan tiap bulannya paling banyak dapat mencapai 199 kunjungan.
Indikator untuk melihat pelaksanaan pemeriksaan gula darah di puskesmas ' $\mathrm{X}$ ' ini meliputi proses pelaksanaan, pencatatan, fasilitas, sumber daya manusia, kendala dan upaya untuk mengatasi kendala tersebut jika ada. Cara untuk mengetahui indikator tersebut digunakan metode observasi, wawancara mendalam dan lembar tilik observasi, terhadap informant utama dan informant kunci. 
Tabel 2 Gambaran Pelaksanaan Pemeriksaan Gula Darah Puasa di Puskesmas ' $\mathrm{X}$ ' Kota Dumai Berdasarkan Hasil Wawancara Mendalam

\begin{tabular}{|c|c|}
\hline \multicolumn{2}{|l|}{ Proses } \\
\hline $\begin{array}{l}\bullet \\
\bullet \\
\bullet\end{array}$ & $\begin{array}{l}\text { Pemeriksaan tekanan darah, berat badan, tinggi badan dan kadar gula darah. } \\
\text { Anamnesis, pemeriksaan fisik, menyarankan pemeriksaan penunjang, } \\
\text { diagnosis, pemberian terapi dan edukasi. } \\
\text { Pemeriksaan gula darah puasa di laboratorium dengan perawat menggunakan } \\
\text { strip glukosa. } \\
\text { Memberikan anjuran pemeriksaan gula darah setiap bulan kepada pasien DM }\end{array}$ \\
\hline \multicolumn{2}{|c|}{ Fasilitas } \\
\hline $\begin{array}{l}\cdot \\
\bullet \\
\bullet \\
\bullet\end{array}$ & $\begin{array}{l}\text { Tempat bagus } \\
\text { Alat-alat lengkap dan cukup } \\
\text { Puskesmas bersih dan nyaman } \\
\text { Pemeriksaan tidak memungut biaya dari pasien }\end{array}$ \\
\hline \multicolumn{2}{|c|}{ Pencatatan } \\
\hline $\begin{array}{l}\bullet \\
\bullet \\
\bullet\end{array}$ & $\begin{array}{l}\text { Sudah baik } \\
\text { Pencatatan dengan aplikasi elektronik yang dinamai Sikda Optima } \\
\text { Tidak ada evaluasi dari pencatatan yang ada sehingga hasil pencatatan tidak } \\
\text { digunakan untuk evaluasi pengobatan pasien DM maupun untuk evaluasi } \\
\text { kinerja pihak puskesmas. } \\
\text { Secara umum pasien DM rutin melakukan pemeriksaan } 1 \text { bulan sekali di } \\
\text { puskesmas }\end{array}$ \\
\hline \multicolumn{2}{|c|}{ Sumber daya manusia } \\
\hline $\begin{array}{l}\bullet \\
\bullet \\
\end{array}$ & $\begin{array}{l}\text { Jumlah perawat lebih dari cukup } \\
\text { Jumlah dokter cukup } \\
\text { Tenaga kesehatan yang ada sudah cukup } \\
\end{array}$ \\
\hline \multicolumn{2}{|c|}{ Kendala dan Upaya } \\
\hline $\begin{array}{l}\text { Kendal } \\
\bullet \\
\bullet \\
\text { Upaya } \\
\bullet \\
\bullet\end{array}$ & $\begin{array}{l}\text { Strip glukosa yang sewaktu-waktu bisa habis } \\
\text { Antrian yang lama jika pasien puskesmas ramai } \\
\text { Tenaga kesehatan laboratorium hanya } 1 \text { orang } \\
\text { Menunggu pengiriman alat pemeriksaan gula darah dari dinas kesehatan } \\
\text { provinsi } \\
\text { Penambahan tenaga kesehatan di laboratorium }\end{array}$ \\
\hline
\end{tabular}

Berdasarkan hasil wawancara mendalam dan observasi terhadap pasien DM dan petugas kesehatan di Puskesmas ' $\mathrm{X}$ ' Kota Dumai mengenai pelaksanaan pemeriksaan $\mathrm{HbA1C}$ di puskesmas ini, didapatkan hasil sebagai berikut. 
Tabel 3 Gambaran pemeriksaan HbA1C di Puskesmas 'X' Kota Dumai

\begin{tabular}{|c|c|}
\hline Proses & \\
\hline $\begin{array}{l} \\
\bullet \\
\bullet \\
\bullet \\
\bullet\end{array}$ & $\begin{array}{l}\text { Tidak pernah melakukan pemeriksaan } \mathrm{HbA} 1 \mathrm{C} \\
\text { Tidak pernah mendapat anjuran dari dokter } \\
\text { Perawat tidak pernah memeriksa kadar HbA1C pasien DM } \\
\text { Dokter tidak pernah menganjurkan pemeriksaan HbA1C } \\
\text { Tidak ada SOP }\end{array}$ \\
\hline \multicolumn{2}{|c|}{ Fasilitas } \\
\hline \multicolumn{2}{|r|}{$\begin{array}{ll}\text { - } & \text { Tempat bagus } \\
\text { - } & \text { Tidak ada alat-alat untuk pemeriksaan HbA1C } \\
\text { - } & \text { Puskesmas bersih dan nyaman } \\
\text { - } & \text { Pemeriksaan tidak memungut biaya pasien }\end{array}$} \\
\hline \multicolumn{2}{|c|}{ Pencatatan } \\
\hline$\bullet$ & $\begin{array}{l}\text { Tidak ada pencatatan karena puskesmas tidak pernah menyediakan } \\
\text { pemeriksaan HbA1C }\end{array}$ \\
\hline \multicolumn{2}{|c|}{ Sumber daya manusia } \\
\hline $\begin{array}{l} \\
\bullet \\
\end{array}$ & $\begin{array}{l}\text { Jumlah perawat lebih dari cukup } \\
\text { Jumlah dokter cukup } \\
\text { Tenaga kesehatan yang ada sudah cukup }\end{array}$ \\
\hline \multicolumn{2}{|c|}{ Kendala dan Upaya } \\
\hline \multicolumn{2}{|r|}{$\begin{array}{l}\text { Kendala } \\
\text { - Tidak adanya fasilitas dan anjuran dari petugas kesehatan mengenai } \\
\text { pemriksaan HbA1C } \\
\text { - Tidak Adanya fasilitas yang diberikan oleh dinas provinsi untuk pemeriksaan } \\
\text { UbA1C di puskesmas } \\
\text { Upaya }\end{array}$} \\
\hline $\begin{array}{c}\text { Upaya } \\
\bullet\end{array}$ & $\begin{array}{l}\text { Menyarankan dan memberikan anjuran kepada pasien untuk melakukan } \\
\text { pemeriksaan gula darah di puskesmas }\end{array}$ \\
\hline
\end{tabular}

Indikator untuk melihat pelaksanaan pemeriksaan HbA1C di Puskesmas ' $\mathrm{X}$ ' ini meliputi proses pelaksanaan, pencatatan, fasilitas, sumber daya manusia, kendala dan upaya untuk mengatasi kendala tersebut jika ada. Cara untuk mengetahui indikator tersebut digunakan metode observasi, wawancara mendalam dan lembar tilik observasi, terhadap informant utama dan informant kunci.

Tabel 4 Gambaran Pelaksanaan Pemeriksaan Pemantauan Gula Darah Mandiri Pasien DM di Puskesmas ' $\mathrm{X}$ ' Kota Dumai Berdasarkan Wawancara Mendalam

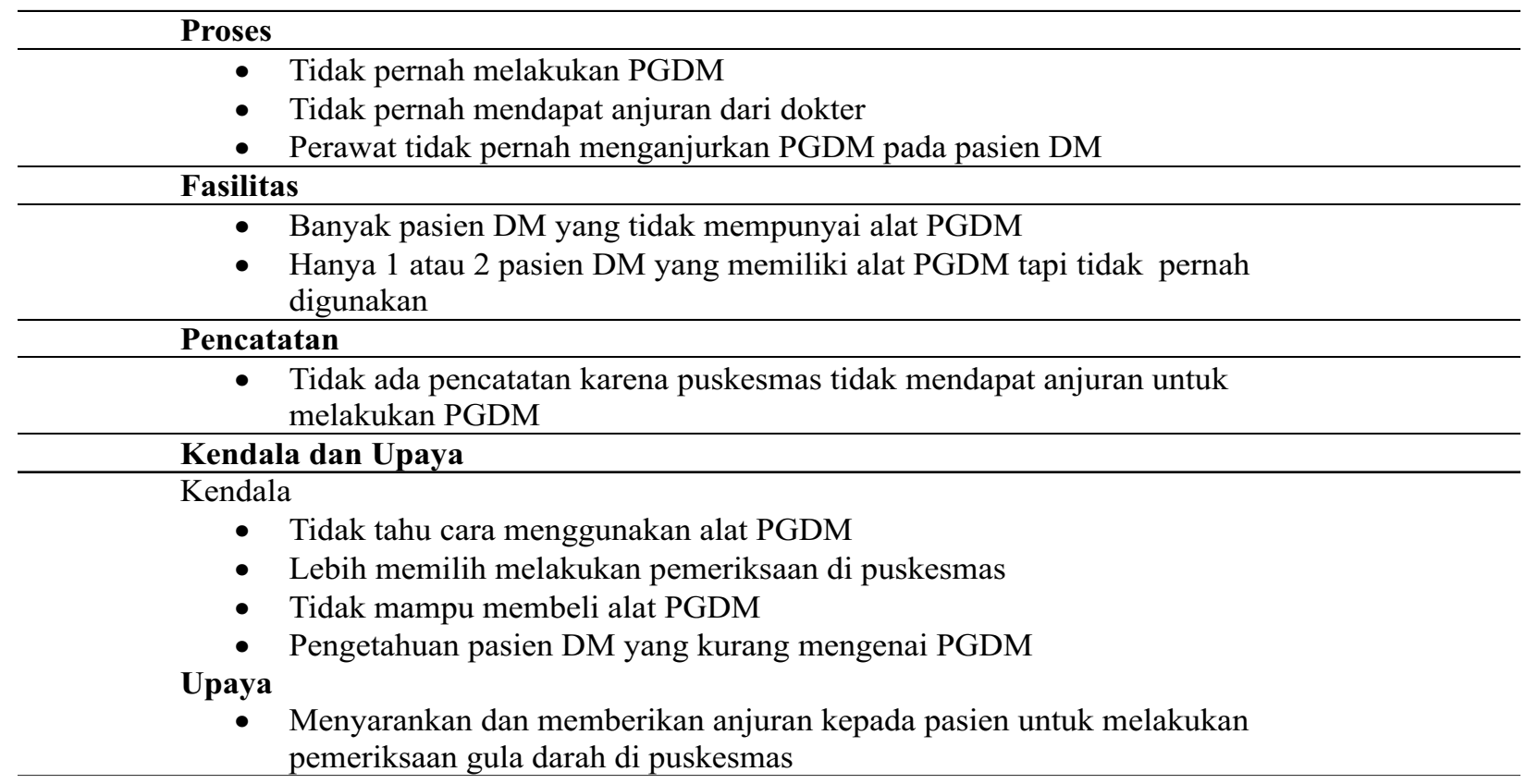




\section{PEMBAHASAN}

Standar pemeriksaan kadar gula darah di pelayanan kesehatan dilakukan minimal tiga bulan sekali setelah kunjungan pertama. American Diabetes Associations (ADA) merekomendasikan kadar ideal yang diharapkan untuk gula darah puasa adalah $80-120 \mathrm{mg} / \mathrm{dl} .{ }^{5}$ Hasil penelitian yang dilakukan di Puskesmas ' $X$ ' Kota Dumai menunjukan bahwa dari 7 pasien DM hanya 4 pasien DM yang teratur memeriksakan kadar gula darah setiap bulannya selama tiga bulan terakhir. Penyebab tiga pasien DM lainnya tidak melakukan pemeriksaan secara teratur adalah kurangnya tingkat kesadaran pasien yang membuat pasien DM datang ke puskesmas hanya ketika sakit walaupun mendapat anjuran untuk melakukan pemeriksaan rutin oleh dokter.

Salah satu faktor yang menyebabkan rendahnya kesadaran pasien adalah locus of control internal, yaitu sebuah penguatan diri pada pasien yang mengidentifikasikan bahwa individu percaya bahwa penyakit datang dari dirinya sendiri sehingga ia bertanggung jawab atas apa yang akan dialaminya. Jika tingkat locus of control internal pasien DM rendah, maka tingkat kesadaran untuk memperhatikan kesehatannya (melakukan kontrol kadar gula darah secara teratur) juga akan menurun. ${ }^{6}$

Penelitian yang dilakukan di Puskesmas ' $\mathrm{X}$ ' Kota Dumai mengenai proses pemeriksaan pasien DM didapatkan hasil yang sesuai dengan pedoman praktik klinik dokter fasilitas kesehatan primer. Hasil yang sama juga didapatkan pada penelitian Rahma dkk di Puskesmas Juwana Kabupaten Pati bahwa sebesar 705 Puskesmas Juwana telah melaksanakan fungsi pokok pelayanan puskesmas sesuai dengan pedoman. ${ }^{7}$ Salah satu faktor penting yang menunjang berjalannya proses pemeriksaan gula darah ini tentunya tersedia fasilitas yang memadai.

Suatu program atau pelayanan tidak dapat berjalan dengan baik tanpa adanya sumber daya yang memadai. ${ }^{8}$ Menurut observasi yang dilakukan didapatkan hasil bahwa perawat dan dokter yang ada di puskesmas ini memang mencukupi untuk melakukan pelayanan pada pasien DM. Terlihat dari banyaknya jumlah perawat di loket, poli maupun di laboratorium. Hal ini membuat pasien DM dapat ditangani dengan baik oleh pihak puskesmas.
Pemeriksaan gula darah di Puskesmas ' $\mathrm{X}$ ' masih terdapat kendala. Salah satu kendalanya adalah strip glukosa atau alat untuk pemeriksaan gula darah sewaktu-waktu bisa habis. Hal ini dikarenakan banyaknya pasien DM yang memeriksakan kadar gula darahnya ke puskesmas, yang menyebabkan alat yang tersedia habis. Kendala lainnya mengenai tenaga kesehatan yang tidak ada pada saat pasien ingin melakukan pemeriksaan.

Deteksi dini dan pencegahan untuk untuk penyakit degeneratif seperti DM masih belum menjadi prioritas utama bagi pemerintah dalam millennium development goals (MDGS) Indonesia. Hal ini tentunya akan mempengaruhi keterbatasan jumlah alat pemeriksa gula darah. Keterbatasan ini tentunya akan berpengaruh terhadap pemberian layanan puskesmas dan pelaksanaan program puskesmas. ${ }^{9}$

Secara keseluruhan, Puskesmas'X'telah melaksanakan pemeriksaan gula darah, tetapi tidak semua pasien melaksanaan pemeriksaan gula darah secara teratur. Hasil penelitian ini sejalan dengan penelitian yang telah dilakukan di Rumah Sakit Jiwa Prof. Dr. Soerojo Magelang, bahwa secara umum pelaksanaan kontrol gula darah tidak teratur dan mengakibatkan pasien tidak teratur melakukan kontrol gula darah. ${ }^{10}$ Pernyataan ini diperkuat dengan penelitian yang dilakukan Nur dan Sari di Puskesmas Jayabaru Kota Banda Aceh, secara keseluruhan pasien DM sudah mengetahui pemeriksaan gula darah walaupun masih terdapat kendala dalam pelaksanaannya. ${ }^{11}$

Tahun 2010 American Diabetes Association memasukan kadar $\mathrm{HbA} 1 \mathrm{C}$ dalam kriteria diagnosis diabetes. HbA1C memiliki kelebihan dibanding dengan pemeriksaan glukosa puasa dan tes glukosa 2 jam. ${ }^{12}$ Kenyataannya dari hasil penelitian, fasilitas untuk pemeriksaan $\mathrm{HbA} 1 \mathrm{C}$ tidak tersedia di puskesmas. Hal ini menyebabkan penderita DM di Puskesmas' $X$ 'pun tidak mendapatkan haknya dalam pelayanan minimal yang seharusnya mereka terima di puskesmas.

Selain hasil wawancara, observasi yang dilakukan juga mendapatkan bahwa Puskesmas ' $X$ ' ini memang tidak melakukan pemeriksaan $\mathrm{HbA} 1 \mathrm{C}$. Tidak tersedianya alat pemeriksaan $\mathrm{HbA} 1 \mathrm{C}$ adalah penyebabnya. Informasi yang didapatkan juga bahwa tidak hanya Puskesmas ' $X$ 'ini saja yang tidak 
melakukan pemeriksaan HbA1C di Kota Dumai.

Deteksi dini dan pencegahan untuk penyakit degeneratif seperti DM masih belum menjadi prioritas utama bagi pemerintah dalam millennium development goals (MDGS) Indonesia yang meliputi penurunan angka kematian ibu dan anak, penurunan angka kemiskinan dan kelaparan, serta memerangi penyakit menular seperti HIV/AIDS dan malaria. Hal ini tentunya akan mempengaruhi keterbatasan jumlah alat pemeriksa gula darah, termasuk HbA1C. Keterbatasan ini tentunya akan berpengaruh terhadap pemberian layanan puskesmas dan pelaksanaan program puskesmas. ${ }^{9}$

Hasil observasi, wawancara di Puskesmas'X'Kota Dumai dan hasil penelitian sebelumnya, didapatkan bahwa masih banyak pasien yang tidak mengetahui tentang pemeriksaan $\mathrm{HbA1C}$ dikarenakan tidak tersedianya fasilitas untuk pemeriksaan ini di puskesmas. Penelitian sebelumnya juga menyebutkan masih banyak bahkan sebagian besar puskesmas di Indonesia tidak mempunyai fasilitas untuk pemeriksaan HbA1C. Ketidaktersediaan ini menyebabkan tidak terlaksananya pemeriksaan $\mathrm{HbA} 1 \mathrm{C}$ untuk pasien DM, padahal pasien DM memiliki hak untuk mendapatkan pemeriksaan ini di fasilitas kesehatan tingkat pertama atau biasa disebut puskesmas.

American Diabetes Association memasukkan PGDM sebagai bagian dari intervensi multifaktorial. Hal ini menunjukan bahwa PGDM adalah komponen terapi yang efektif. ${ }^{13}$ Informasi mengenai pelaksanaan PGDM oleh pasien DM di Puskesmas 'X'didapatkan bahwa sebagian besar pasien tidak melakukan PGDM. Walaupun sebagian besar pasien DM di puskesmas ini tidak melakukan PGDM dikarenakan tidak mempunyai alatnya, terdapat satu pasien DM yang menyatakan bahwa ia memiliki alat pemeriksa gula darah di rumah. Meskipun memiliki alat untuk melakukan PGDM, pasien DM ini tetap memilih untuk melakukan pemeriksaan gula darah di puskesmas dengan alasan jika pemeriksaan gula darah yang dilakukan di puskesmas akan dilakukan oleh laboran yang tentunya lebih paham cara pemakaian alatnya dan puskesmas juga memiliki dokter yang bisa untuk memberikan terapi dan berkonsultasi dengan pasien setelah dilakukan pemeriksaan gula darah.
Faktor yang mempengaruhi pasien tidak melakukan pemantauan gula darah mandiri yang didapatkan dari pasien DM di Puskesmas ' $\mathrm{X}$ ' adalah tidak memiliki alat dan status ekonomi yang menyebabkan pasien DM tidak mampu membeli alat pemeriksaan gula darah. Hal ini sejalan dengan penelitian yang dilakukan di poliklinik penyakit dalam RSUD Mokopido Toli-Toli, bahwa masih banyak pasien yang belum melakukan pemantauan gula darah mandiri yang disebabkan status sosial ekonomi. ${ }^{14}$

Hasil observasi dan wawancara mendalam dengan pasien DM didapatkan masih rendahnya pelaksanaan PGDM oleh pasien DM di Puskesmas ' $X$ 'Kota Dumai. Hal ini disebabkan pasien DM yang tidak memiliki alat pemeriksaan gula darah, tidak adanya anjuran, rendahnya pengetahuan dan lebih memilih untuk memeriksakan kadar gula darahnya di Puskesmas.

\section{SIMPULAN}

Gambaran pelaksanaan pemeriksaan kadar gula darah di Puskesmas ' $X$ 'menurut hasil wawancara dengan informant dan observasi sudah berjalan dengan baik. Pencatatan hasil pemeriksaan dilakukan tetapi tidak dilakukan evaluasi terhadap hasil pencatatan terhadap pasien DM. Tidak adanya pelaksanaan pemeriksaan HbA1C di Puskesmas' $X$ ' dikarenakan belum tersedianya fasilitas tersebut. Sebagian besar pasien DM di Puskesmas ' $X$ ” tidak melakukan PGDM.

\section{DAFTAR PUSTAKA}

1. Diabetes Association. Diagnosis and classification of diabetes melitus. Diabetic Care. 2012;35 suppl:568.

2. Olokoba AB, Obateru OA, Olokoba LB. Type 2 Diabetes melitus: A review of current trends. Oman Medical Journal. 2012. 27(4) suppl : 269273.

3. Dep Kes RI. Pokok-pokok hasil riset kesehatan dasar (Riskesdas) Provinsi Riau 2013. Badan penelitian dan pengembangan kesehatan. 2013.

4. Perkumpulan Endokrinologi Indonesia (PERKENI). Konsensus pengelolaan dan 
pencegahan diabetes melitus tipe 2 di Indonesia. 2015.

5. Buku Panduan Pelayanan Laboratorium Puskesmas Bara Permai. [Update 2017]

6. Safitri IN. Kepatuhan penderita diabetes melitus tipe ii ditinjau dari lokus of control. J Ilm Psikol Terap. 2013;1:18.

7. Rahma Ainur, Arso. Implementasi fungsi pokok pelayanan primer puskesmas sebagai gatekeeper dalam program jkn (studi di puskesmas juwana kabupaten pati). [Skripsi] Fakultas Kesehatan masyarakat Universitas Diponegoro. 2015.

8. Purwitayana, Dewa Putu Agung. Faktor-faktor determinan yang mempengaruhi implementasi program jaminan kesehatan Bali Mandara di RSUD Wangaya Denpasar. [Skripsi]. Program Studi Ilmu Administrasi Negara, Universitas Airlangga, 2013.

9. Subramaniam, Kumudini. Faktor-faktor yang mempengaruhi keterlambatan diagnosis diabeters melitus tipe 2 di Wilayah kerja Puskesmas Abang I, Kabupaten karangasem Bali. [Skripsi]. Pendidikan Dokter Fakultas Kedokteran Universitas Udayana. 2015.
10.Panduan Praktik Klinis Bagi Dokter di Fasilitas Pelayanan Kesehatan Primer. [Update 2014].

11. Ramadhan, Nur. Kontrol glikemik pada penderita diabetes melitus tipe 2 di Puskesmas Jayabaru Kota Banda Aceh. Loka Penelitian dan Pengembangan Biomedis Aceh. 2015.

12.Paputungan Sri Rahayu, Sanusi Harsinen. Peranan pemeriksaan hemoglobin a1c pada pengelolaan diabetes melitus. CDK-220/41 (9). 2014.

13. American Diabetes Association. Standards of medical care in diabetes. Diabetes Care. 2004;27(Suppl 1):S15-S35.

14. Wakhyuni Budiarto Kusumo, Arifiyanto Dafid. Gambaran perilaku pelaksananaan pemantauan glukosa darah mandiri dan perilaku olahraga pada anggota persadia Unit RSUD Kraton Kabupaten Pekalongan. Stikes Muhammadiyah Pekajangan Pekalongan. 2014. 